\title{
Capsule Commentary on Kern et al., Patients' and Providers' Views on Causes and Consequences of Healthcare Fragmentation in the Ambulatory Setting: a Qualitative Study
}

\author{
Parker Magin, PhD, FRACGP
}

School of Medicine and Public Health, University of Newcastle, Callaghan, Australia.

J Gen Intern Med 34(6):1004

DOI: $10.1007 / \mathrm{s} 11606-019-04903-0$

(c) Society of General Internal Medicine 2019

A ragmentation of care and consequent lack of continuity of care are key issues in primary care. Continuity of care is a defining attribute of primary care, ${ }^{1}$ and concern regarding increasing fragmentation/poor continuity of care in primary care has often been expressed. ${ }^{2}$ Continuity of care is particularly important for patients with multimorbidity, but there is evidence that continuity of care is inversely associated with multimorbidity in primary care. ${ }^{3}$ While previous qualitative research has explored patients' perceptions of continuity of care, ${ }^{4}$ the linked study by Kern et al. ${ }^{5}$ adds to our understanding of why and how care fragmentation occurs, and how it affects primary healthcare delivery.

Kern et al. used a qualitative methodology to triangulate patient and clinician perspectives of causes and consequences of care fragmentation in patients with multimorbidity $(\geq$ two chronic conditions). The authors found a range of perceived causes and consequences operating at patient, provider, healthcare organization, and healthcare environment levels. An overarching finding was that fragmentation and its sequelae are complex and not just "a function of sicker patients seeing more providers."

Their qualitative methodology (including the ideasgeneration afforded by a focus group format) has resulted in a fine-grained, nuanced understanding of the drivers and consequences of fragmentation of care in primary care patients with multimorbidity. The importance of these findings is that they could inform practice and policy at the levels of individual patient/healthcare provider interaction, healthcare facility, and wider health systems.

There are limitations, however, to interpreting and using these findings to frame practice and policy in addressing fragmentation of care in primary care. The major issue is how transferable the findings are to other settings, especially other healthcare systems internationally (including healthcare systems with very different healthcare funding/insurance systems). That the study was conducted in a single academic hospital-based primary care practice, and that sampling was not purposive, raises concerns in this area. Clinicians, administrators, and policy-makers should carefully consider the contextual information regarding the study setting presented in the paper in evaluating the implications of the results. Contextualized, the study findings may usefully inform responses to fragmentation of care in their practices and systems.

Corresponding Author: Parker Magin, PhD, FRACGP; School of Medicine and Public Health, University of Newcastle, Callaghan, Australia (e-mail: parker.magin@newcastle.edu.au).

\section{Compliance with Ethical Standards:}

Conflict of Interest: The author declares that he does not have a conflict of interest.

Publisher's Note: Springer Nature remains neutral with regard to jurisdictional claims in published maps and institutional affiliations.

\section{REFERENCES}

1. Starfield B, Shi L, Macinko J. Contribution of primary care to health systems and health. Milbank Q 2005;83:457-502.

2. Guthrie B, Saultz JW, Freeman GK, Haggerty JL. Continuity of care matters. BMJ 2008;337:a867.

3. Salisbury C, Johnson L, Purdy S, Valderas JM, Montgomery AA. Epidemiology and impact of multimorbidity in primary care: a retrospective cohort study. Br J Gen Pract 2011;61:e12-21.

4. Waibel S, Henao D, Aller MB, Vargas I, Vazquez ML. What do we know about patients' perceptions of continuity of care? A meta-synthesis of qualitative studies. Int J Qual Health Care 2012;24:39-48.

5. K Kern LM, Safford M, Slavin MJ, Makovkina E, Fudl A, Carrillo E, Abramson EL. Patients' and Providers' Views on Causes and Consequences of Healthcare Fragmentation in the Ambulatory Setting: A Qualitative Study. J Gen Intern Med. https://doi.org/10.1007/s11606019-04859-1. 